\title{
Propiedad y derechos eclesiásticos en Villavicencio: un litigio entre el abad de Sahagún y el episcopado leonés*
}

\author{
Fernando Luis Corral \\ Universidad de Salamanca
}

\begin{abstract}
RESUMEN
En el año 1216 el papa Inocencio III emitia una sentencia en torno a un largo litigio que la sede episcopal de León mantenía con el monasterio de Sahagún por las rentas eclesiásticas de las iglesias del coto monástico que estaban a su vez dentro de la demarcación diocesana leonesa. Vamos a prestar atención al caso concreto de las iglesias de Villavicencio y a la actitud del abad de Sahagún de no satisfacer al obispo de León las tercias decimales que le reclamaba. Ante esta pretensión del episcopado leonés de hacer efectiva su jurisdicción diocesana, el abad de Sahagún esgrimía la posesión de un privilegio papal que le confería inmunidad para percibir en su totalidad las rentas eclesiásticas que se derivaban de estas iglesias. Se trata, por tanto, del análisis de un conflicto jurisdiccional por el acceso a la renta eclesiástica de las iglesias de la villa y una lucha por establecer

la primacía de la jurisdicción episcopal por encima de la jurisdicción particular de un
\end{abstract}

\begin{abstract}
In the year 1216 the Pope Inocencio III issued a judgment about a long dispute between the León episcopate and the monastery of Sahagún, about the ecclesiastical rents of the churches of that monastery territory, that were, at the same time, included in the diocese of León.

We will pay special attention to the specific case of the Villavicencio churches, and the attitude of the Sahagún abbot to deny the payment of the tithe tierces claimed by the León bishop. With regard to the episcopate claim to carry out the diocesan rules, the Sahagun abbot argued the possession of a pope privilege consisting of the immunity to obtain the total amount of the ecclesiastical rents from the these churches.

Therefore, this is an analisis of a legal conflict for the acquisition of ecclesiastical rents from these churches and the struggle to stablish the primacy of the episcopate jurisdiction over the particular jurisdiction of a monastery; that
\end{abstract}

El presente trabajo fue el fruto de una comunicación presentada al $X$ Congreso de Historia Agraria celebrado en Sitges en el año 2002 
monasterio que actúa como un señorío más dentro de la villa.

\section{PALABRAS CLAVE}

Edad Media, Península lbérica, León, Sahagún, catedral, monasterio, litigio, Villavicencio, renta, jurisdicción, diezmo, propiedad, diócesis, coto monástico. behaved as one seigniory among others in that village.

\section{KEYWORDS}

Middle Ages, Iberian Peninsula, León, Sahagún, cathedral, monastery, dispute, Villavicencio, rent, jurisdiction, tithe, property, diocese, monastery territory.

La importancia de Villavicencio ${ }^{1}$ en la Edad Media castellano-leonesa se debió sobre todo a dos factores. De un lado, su posición fronteriza entre los reinos de León y de Castilla en el período de su fragmentación tras la muerte de Alfonso VII y hasta su reunificación en tiempos de Fernando III. Por otro lado, en Villavicencio se dieron cita una nutrida representación de señores laicos y eclesiásticos con propiedades y derechos sobre el lugar y sus habitantes. Esta última circunstancia propició la concesión de varios fueros a la villa desde el año 1091 con los que se quiso regular la conflictividad jurisdiccional a la que se vio sometido este espacio ${ }^{2}$.

Villavicencio experimentó un desarrollo demográfico continuado desde finales del siglo $X$ y los inicios del siglo siguiente ${ }^{3}$, algo que viene a ser confirmado por la progresiva construcción de iglesias en su término municipal. En el acta de conciliación que firmaron María Gómez y sus hijos con el abad de Sahagún en el año $1136^{4}$, se mencionaron las iglesias de la villa, pero no será hasta diez años más tarde cuando conozcamos el nombre de una de ellas bajo la advocación de Santa María ${ }^{5}$. En 1163, un documento de protección del papa Alejandro III al monasterio de Sahagún reafirmó este crecimiento, incluso frente a Villa Motarraf, lugar desde el que se organizó el territorio y el poblamiento de la zona en los inicios del siglo $X^{6}$, que en esos momentos posiblemente sólo poseía una iglesia, pues se constata la presencia de varias iglesias en Villavicencio ${ }^{7}$; los nombres de éstas fueron es-

\footnotetext{
El actual Villavicencio de los Caballeros en la provincia de Valladolid.

${ }^{2}$ Luis Corral, F., Villavicencio en la Edad Media. Propiedad y Jurisdicción en los valles del Cea y del Valderaduey, Valladolid, 2003, pp. 167 y ss.

${ }^{3}$ lbidem, pp. 89 y ss.

“GonzAlez Diez., E., El régimen foral vallisoletano. Una perspectiva de análisis organizativo del territorio, Valladolid, 1986, doc. VII, pp. 95-97.

${ }^{5}$ Fernández Flótez, J.A., Colección diplomática del Monasterio de Sahagún, vol. IV (1110-1199), León, 1991, doc. 1290, pp. 196-197.

${ }^{6}$ LuIS CORRAL, F., Op. cit., esp. el capítulo dedicado a la articulación del poblamiento y del territorio por el presbítero Vincemalo.

FERNÁNDEZ Florez, J. A., Sahagún, vol. IV, doc 1348, pp. 301-304. Con todo se podría argumentar que el reconocimiento del Papa de derechos de Sahagún sobre la iglesia de Villa Motarraf, no quiere decir explicitamente que no hubiese más iglesias en esta villa, aunque por otro lado, sería extraño que de haber
} 
pecificados más tardíamente, al final del siglo XII, cuando Celestino III expidió un privilegio en el año 1194 para confirmar las posesiones del cenobio de Sahagún e hizo constar entre ellas la de San Pedro de Villa Motarraf y las iglesias de San Pelayo, Santa María y San Pedro en Villavicencio ${ }^{8}$.

La proliferación de iglesias no es un dato menor. En la conciliación a la que hacíamos alusión entre María Gómez y sus herederos y el monasterio de Sahagún se decía en uno de sus puntos:

"Et ut nulla ecclesia ibi habeatur nisi de Sancto Facundo, cum suis dextris, cum suis cimiteriis et cum suis clericis et cum suis decimis et suis primitiis et cum toto suo offerto et cum toto suo mortuorum»"

La posesión de derechos, entre los que se encontraban los diezmos y primicias, por parte del monasterio se traducia en el incremento de ingresos a través de las rentas que esos derechos podian devengar. No se podría entender la consolidación del dominio del monasterio de Sahagún sobre la viIla, tan sólo a través del patrimonio que éste había sido capaz de acumular fruto de las donaciones y de las compras. Los ingresos que percibió por los derechos que le correspondian en las iglesias o por la posesión de los molinos ${ }^{10}$, aseguraron su supervivencia y la posibilidad de dedicar los excedentes a nuevas compras patrimoniales ${ }^{11}$.

El abad de Sahagún era quien ejercía la jurisdicción eclesiástica en las tres iglesias de la villa, a pesar de que éstas se encontraban en la diócesis del obispo de León. Todo tenía su origen en los privilegios que el monasterio había conseguido de los reyes y del papa que liberaban de la jurisdicción episcopal al monasterio y sus propiedades. Esta inmunidad de la que disfrutaba el monasterio entraba en conflicto con la demarcación diocesana en la que el obispo de León ejercia su señorío episcopal, y donde tenía derecho a percibir una serie de rentas derivadas de su condición eclesiástica. Una vez que se estabilizó la situación política en el reinado de Alfonso VI, y las co-

más iglesias en Villa Motarraf el monasterio de Sahagún no hubiera tenido alli derechos teniendo en cuenta que esta villa estaba entre sus propiedades desde el año 970, antes incluso de que Villavicencio se hubiera desarrollado como núcleo de población importante.

${ }^{8}$ Ibidem, doc. 1489, pp. 503-507.

${ }^{9}$ González Diez., El régimen foral vallisoletano, doc. VII, pp. 95-97.

${ }^{10}$ LuIs CorRal, F., op. cit., pp. 128 y ss.

"José Luis Martín, refiriéndose a los diezmos eclesiásticos en Zamora reinvidicaba la importancia de éstos: "La base de los dominios son las donaciones complementadas por las compras, pero ni las donaciones bastarian por si solas para asegurar la continuidad, extensión y perfeccionamiento del dominio, ni las compras pueden explicarse sin conocer la procedencia del dinero invertido. Los fueros y contratos agrarios permiten la consolidación juridico-económica y la explotación del dominio, y los derechos eclesiásticos, los diezmos, entre ellos, son una fuente importante de ingresos en productos $y$ en dinero $y$ hacen posible la supervivencia de los eclesiásticos, la existencia de sobrantes y su dedicación a la compra de nuevos bienes", vid. MARTín ROdRiguez, J-L., "Diezmos eclesiásticos", en Amor, cuestión de señorio y otros estudios zamoranos, UNED, Zamora, 1993, pp. 53. 
marcas al norte del Duero dejaron de sufrir las incursiones musulmanas, los obispados se consolidaron y trataron de hacer efectiva su jurisdicción en la diócesis exigiendo las rentas correspondientes en las iglesias que estaban dentro de ese ámbito jurisdiccional. Los territorios inmunes como el del monasterio de Sahagún también estaban dentro de esa diócesis y el obispo de León quiso percibir de esas iglesias las tercias decimales que le correspondían. Fue aquí donde se produjo el choque frontal entre los intereses episcopales y los del abadengo de Sahagún, que en virtud de algunos privilegios estaba autorizado a ejercer la jurisdicción en materia eclesiástica en esas iglesias.

En el año 1091 -el mismo en el que el abad se tuvo que enfrentar a los campesinos de Villavicencio asentados en sus solares ${ }^{12}$ - hizo frente a las reclamaciones del obispo de León por el cobro de las tercias decimales de las iglesias que, estando bajo su dominio, se encontraban en la diócesis leonesa. La mediación del arzobispo de Toledo, don Bernardo, ayudó a que el monasterio siguiera manteniendo el cobro de las tercias frente al obispo de León, don Pedro, que aceptó no reclamar esta renta en las iglesias que el abad de Sahagún enumeró, entre ellas, la iglesia de Villa Motarraf, y las iglesias de sus aldeas ${ }^{13}$. Este acuerdo se debió de producir tras haberse dado entre las dos partes una serie de roces en esa lucha por el control de los diezmos eclesiásticos.

Tras el acuerdo se produjeron una serie continuada de confirmaciones por parte de distintos pontífices de las posesiones del monasterio de Sahagún y de sus derechos sobre las iglesias que estaban bajo su dominio. En marzo de 1116 fue Pascual II, quien confirmando las concesiones de sus predecesores, Gregorio VII y Urbano II, amparó al monasterio de Sahagún tomándolo bajo su protección y enumeró y confirmó las donaciones de villas e iglesias que pertenecían al coto del monasterio, encontrándose de nuevo entre ellas Villa Motarraf y sus aldeas, de manera que la iglesia de la villa seguiría entregando sus diezmos al abad y no al obispo de León ${ }^{14}$. El sucesor de Pascual II, el papa Eugenio III, repitió lo que ya habían hecho sus predecesores, aunque en este documento, cuando se menciona a Villa Motarraf ya no se habla de la villa y sus aldeas, sino de la iglesia de la villa y sus iglesias. Creemos que el redactor del documento se refiere a las iglesias que estaban en las aldeas cercanas a Villa Motarraf y que dependerían de la iglesia de la villa ${ }^{15}$. El 19 de junio del año 1163 , el papa Alejandro III, sucesor de Eugenio III, confirmó de nuevo las posesiones y derechos del monas-

\footnotetext{
Vid. Luis Corral, F., op. cit., pp. 170 y ss.

13 "... In Aratori... Villa Mutarraf, cum villulis suis...", vid. HeRrero dE LA FUENTE, M., Colección diplomática del Monasterio de Sahagún, vol. Ill (1074-1109), León, 1988, doc. 885, pp. 199.

"4 "... in Aratoi... Villam Mudarraf cum villis suis...", vid. FERnÁndez FlóREZ, J.A., Sahagún, vol. IV, doc. 1194, pp. 45.

15. "..ecclesiam de Villa Modarrat, cum ecclesiis suis...", vid. Ibídem, doc. 1296, pp. 206.
} 
terio de Sahagún, mencionando las iglesias que estaban en el coto del monasterio, entre ellas la de Villa Motarraf y se mencionan, por primera vez, las iglesias de Villavicencio ${ }^{16}$.

El amparo de la Sede Pontificia y el acuerdo al que habían llegado en el año 1091 no fueron suficientes para que los sucesivos obispos de León no inquietaran al monasterio de Sahagún en el cobro de las rentas eclesiásticas que reclamaban en su diócesis. Los funcionarios de la catedral debieron exigir las tercias en las iglesias de la villa de Sahagún, porque en el año 1181, el papa Alejandro III tuvo que comisionar a los obispos de Palencia, Ávila y Oviedo para que resolvieran este litigio entre las dos entidades eclesiásticas sobre el cobro de las tercias ${ }^{17}$. La lucha por las rentas continuó, como lo demuestran las llamadas al orden del papa a los contendientes. En 1184 , se comisionó a los obispos de Palencia y de Ávila para que ordenasen a los monjes y al abad del monasterio de Sahagún que renunciasen a sus injerencias en las iglesias que jurisdiccionalmente correspondian al obispo de León ${ }^{18}$. Unos meses después, ya en el año 1185, el papa, a través de una comisión integrada por los obispos de Oviedo y Zamora y el abad de Moreruela, volvió a insistir en la orden de que el abad de Sahagún dejará de entrometerse en las iglesias que estaban fuera de Sahagún y del coto del monasterio y que pertenecían a la jurisdicción del obispo de León ${ }^{19}$. El abad de Sahagún no acató los mandatos del papa Lucio, puesto que en el pontificado de Urbano III se siguieron emitiendo desde la cancillería pontificia órdenes directas al abad de Sahagún y al obispo de León para que resolvieran sus disputas por las rentas eclesiásticas, debido a que se continuaban registrando injerencias del abad y sus monjes en parroquias fuera de la villa de Sahagún y del coto monástico, en territorio que jurisdiccionalmente pertenecía al obispo leonés ${ }^{20}$.

El 14 de julio de 1194, Celestino III procedió, como era acostumbrado al inicio del mandato de un nuevo pontífice, a amparar al monasterio y sus propiedades y derechos, enumerando de nuevo todas sus posesiones. El documento guarda el mismo esquema que los diplomas que emitió la cancillería pontificia en otras ocasiones con este fin, pero en este caso se introdujo en el diploma la mención explícita de los nombres de las iglesias

\footnotetext{
${ }^{16}$ "...ecclesiam de Villa Mudaraf, cum ecclesiis de Villavicenz...", vid. Ibidem, doc. 1348, pp. 303.

"Fernandez Catón, J. M.". Colección documental del Archivo de la catedral de León, vol. V (11091187), León, 1990, doc. 1625, pp. 514-515.

18 “...mandamus, quatinus ipsum abbatem et fratres moneatis attentius et inducatis, et si necesse fuerit, appellatione remota, ecclesiastica districtione cogatis, ut memorato episcopo in eiusdem ecclesiis iura sua non subtrahant...", vid. lbidem, doc. 1648. pp. 555.

${ }^{19}$ El 16 de julio de 1185, Lucio III comisionó a los obispos citados y al abad del monasterio cisterciense de Moreruela para que, oidas las partes, juzgasen y ordenasen al abad de Sahagún que cesase en su intromisión en la jurisdicción eclesiástica del obispo de León fuera de la villa de Sahagún y del coto monástico, vid. Ibidem, doc. 1652, pp. 558-559.

${ }^{20}$ Ibidem, doc. 1663, pp. 578-579.
} 
de Villa Motarraf y de Villavicencio, especificando que en esta última había tres parroquias: Ias iglesias de San Pelayo, Santa María y San Pedro, que coinciden con las tres que actualmente se conservan en la villa del Valderaduey ${ }^{21}$.

Se siguieron produciendo los problemas de intromisión del abad de Sahagún en las iglesias del obispo de León. Inocencio III comisionó en junio del año 1198 al obispo y al arcediano de Zamora y a Diego, prior del monasterio de Moreruela, para que zanjasen definitivamente este litigio ${ }^{22}$.

Pero a pesar de todo, continuaron produciéndose enfrentamientos, como se deduce de una relación de lugares que hizo don Rodrigo, obispo de León, donde no se respetaban sus bienes, propiedades y derechos. En esta lista se menciona que los caballeros y herederos de Villavicencio entre los que se encontraba el abad de Sahagún, y el concejo de la villa, no le daban una serie de derechos, entre ellos el prandium ${ }^{23}$.

El litigio entre el abad y el obispo continuó y se llevaron a cabo actuaciones administrativas y judiciales, presentando el abad una serie de testigos ante los obispo de Orense y Segovia que declarasen si las iglesias del coto del monasterio estaban bajo la jurisdicción del abad o del obispo. Por Villavicencio comparecieron once testigos, cuyos nombres eran Martín Facundi, de 60 años de edad, Domingo Baraguto, de 61 años, Juan Salvadórez, de 57 años, Romano, de 46 años, Juan Carpintero, de 60 años, Fernando Guastonis, de al menos 44 años, Marcelo, de 50 años, Juan Toral, de 60 años, Domingo Duradero, de 60 años, Domingo Cipriani, de 50 años y Pedro Facundi, de 40 años de edad, todos ellos laicos y solariegos del abad, excepto este último que era presbítero en Villavicencio y que llevaba viviendo allí desde hacia 30 años. A las preguntas de los obispos respondieron que las tres iglesias de la villa no estaban bajo la jurisdicción del episcopado leonés, aunque circunstancialmente estuvieran dentro de esta diócesis; dijeron que en ellas los caballeros de la villa y el abad ponían un clérigo y el concejo ponía otro, que eran ordenados por el abad, y que no tenían conocimiento de que, alguna vez, estos clérigos hubieran sido convocados o hubieran ido a sínodo a León; declararon que sobre la villa y el coto el abad tenía un privilegio del papa que le otorgaba los derechos para percibir las rentas de las iglesias de la villa; sobre los diezmos dijeron que el abad percibía en San Pelayo dos partes y una los clérigos y en las restantes iglesias

2. "...ecclesia Sancti Petri de Villa Mudarraf; tres ecclesie in Villavincencii, scilicet, Sancti Pelagii et Sancte Marie et Sancti Petri...", vid. Fernandez Florez, J.A., Sahagún, vol. IV, doc. 1489, pp. 505.

"Fefanandez Catón, J. M. a Colección documental del Archivo de la catedral de León, vol. VI (11881230), León, 1991, doc. 1739, pp. 95-96.

${ }^{23}$ “...In Villa Vicenzi iniuriatur nobis milites heredes insuper aqua et rotelis et aliis et concilium non dat nobis prandium... Vassali nostri de Villa Vicenzi non dat nobis prandium quod dare consueverunt episcopo...", vid. Ibídem., doc. 1815, pp. 219. Además de en Villavicencio, el obispo de León tuvo estos problemas en villas cercanas como Castroverde, Villalpando o Villafrechós, entre otras. 
se las repartian a la mitad ${ }^{24}$. Estos dos obispos interrogaron a más testigos, un total de 131, que declararon sobre las iglesias de Sahagún y de las restantes del coto monástico.

Tras estos procedimientos, oídas las partes y presentadas las alegaciones correspondientes, en mayo de 1216, Inocencio lil se pronunció sobre el pleito que durante tanto tiempo venían sosteniendo el obispo de León y el monasterio de Sahagún sobre las iglesias de la villa de Sahagún y las del coto monástico. Envió dos "Litterae executoriae", una al obispo de León para comunicar su decisión, y otra a los obispos de Burgos y Astorga y al abad del monasterio de San Pedro de la Espina, para que ejecutaran su decisión en la que se establecían los derechos que correspondían a cada parte. En virtud de ésta, la villa de Sahagún quedaba libre de la jurisdicción eclesiástica del obispo de León, y en las restantes iglesias del coto del monasterio, el obispo debía percibir lo correspondiente al crisma, el santo óleo, las consagraciones del altar, las ordenaciones de clérigos, y tendría competencia en las penitencias públicas y en las causas matrimoniales, así como recibir la procuración una vez al año ${ }^{25}$. Esta decisión papal se ejecutó por el obispo de Astorga y el abad del monasterio de la Espina tres años después en una concordia en la que firmaron el obispo de León y el abad de Sahagún. En ella se concretaban de qué forma y quiénes iban a percibir los diezmos, procuraciones y el catedrático en Villavicencio y otras cinco villas, a saber, Saelices de Mayorga, Villada, Pozuelos, Saelices del Río y Villafrades, además de en las restantes iglesias que estuvieran dentro o fuera del coto monástico. En la ejecución de la sentencia papal, al obispo de León le correspondían la mitad de las tercias decimales, tanto de pan como de vino, así como de legumbres y lino; en concepto de procuración, las iglesias de estas seis villas debían pagar al obispo anualmente treinta maravedís y al arcediano un áureo; además, cada iglesia del monasterio de estas seis villas, así como las restantes dentro y fuera del coto monástico, debian pagar en concepto de catedrático un carnero al año. Por último, se declaró competente al obispo de León, entre otras cosas, en la corrección de los clérigos, la obediencia de los laicos, la ordenación de clérigos y la llamada a sínodo de éstos ${ }^{26}$.

\footnotetext{
${ }^{24}$ Entre 1213 y 1216 , el obispo de León, don Rodrigo, remitió al obispo de Orense, uno de los jueces en el litigio entre el abad de Sahagún y el obispo de León, sobre la jurisdicción eclesiástica en la villa de Sahagún y en el coto del monasterio, cuatro fórmulas por las que el obispo de Orense debía delegar sus funciones en el obispo de Segovia y el arcediano de Astorga para que se ejecutara la bula papal por la que se debia continuar con el juicio de esta causa y los tres jueces pudieran actuar conjunta o separadamente para resolver el problema, vid. Ibidem, doc. 1828, pp. 236-237.

En 1215, antes del mes de agosto, los obispos de Orense y Segovia procedieron al interrogatorio que hemos resumido para los testigos de Villavicencio, vid. lbidem, doc. 1849, 264-310, y especialmente para lo que se refiere a Villavicencio las páginas $282-284$ y $286-287$

"S Ibidem, doc. 1852 y doc. 1853, pp. 313-316.

${ }^{25}$ Fernandez Flórez, J.A., Colección diplomática del monasterio de Sahagún, vol V (1109-1300), León, 1991, doc. 1620, pp. 125-127.
} 
Con este documento parecía ponerse fin a un largo pleito por el control de las rentas eclesiásticas de las iglesias de las villas que pertenecian al monasterio. Pero esta lucha por la reafirmación de las diócesis episcopales continuó. El monasterio no quería que las rentas que ingresaba por las iglesias que estaban dentro de su coto o las que le pertenecian fuera de él, fueran a parar a manos de ninguna sede episcopal. Por su parte, los titulares de éstas $^{27}$, conscientes de su creciente poder, querían hacer efectivo éste en la demarcación tradicional que les correspondia por este cargo: la diócesis. Dos derechos encontrados que, como hemos comprobado, tuvieron una difícil solución, y que dependió de la fortaleza de cada uno de estos señores eclesiásticos para negociar con la Santa Sede una solución que les beneficiase. La realidad es que a pesar de los acuerdos puntuales, las desavenencias por los límites diocesanos y jurisdiccionales surgían al poco tiempo, fruto de ello fueron los numerosos litigios que se sucedieron en el tiempo hasta bien entrada la Edad Moderna ${ }^{28}$.

A pesar de todo, el dominio que el abad de Sahagún consiguió ejercer sobre las iglesias de Villavicencio fue importante, prorrogando en el tiempo, mediante continuos procesos judiciales, la injerencia del obispo de León, al que le fue siempre difícil hacer efectivo su derecho en ellas. Sin embargo, no tuvo el mismo éxito dentro de la propia villa, ya que si bien en el año 1136 habia conseguido mantener fuera de la percepción de rentas y derechos en las iglesias a la poderosa familia de María Gómez, la tendencia fue cambiando, como se comprueba a través del testimonio recogido por los obispos de Orense y Segovia en agosto del año 1215: el concejo y los caballeros de la villa ponían algunos de los clérigos de las iglesias de Villavicencio. El fortalecimiento que desde el comienzo del siglo XII experimentó el concejo de Villavicencio le habilitó para compartir esta responsabilidad en la villa junto al abad de Sahagún y los caballeros heredados alli ${ }^{29}$.

La conclusión en esta aproximación al problema del litigio jurisdiccional en Villavicencio entre el abad de Sahagún y el obispo legionense parece clara. Ambos negociaron con el papado la resolución del problema tratando de buscar una legitimación de sus derechos sobre el papel, pero como podemos observar por la documentación, el monasterio de Sahagún, omnipresente en la villa y sus alrededores, fue más capaz que la sede leonesa de llevar a cabo ese ejercicio del poder sobre las iglesias de la villa que se tradujo en una acaparación de las rentas que se percibían de ellas.

Principalmente el obispo de León, aunque el titular de la sede episcopal de Palencia también se enfrentó al monasterio: en 1225 el obispo de Palencia y el abad de Sahagún se disputaron los derechos de la iglesia de Villafrades y de otros lugares, vid. Ibidem, doc. 1634, pp. 146-148.

"Fernandez, L., "Villafrades de Campos. Señorio del abad de Sahagún», AL, n. 54 (1973), pp. 234-235.

"Luis Coral, F., "Aportaciones al fuero de Villavicencio de 1221", Studia Historica. Historia Medieval, 17 (1999), pp. 201-213. 